\title{
Semantic, Pragmatic and Cultural Equivalence in the Source Text and Target Text of the Selected Poetry of Amjad Islam Amjad
}

\author{
Ruqia Wazir \\ National College of Business \\ and Administration Lahore, Pakistan
}

Muhammad Arfan Lodhi

Higher Education Department Collegiate

Wing Government of Punjab, Pakistan

samaritan_as@hotmail.com 


\title{
Semantic, Pragmatic and Cultural Equivalence in the Source Text and Target Text of the Selected Poetry of Amjad Islam Amjad
}

\author{
Ruqia Wazira, Muhammad Arfan Lodhi*b \\ a National College of Business and Administration Lahore, Pakistan \\ b Higher Education Department Collegiate Wing Government of Punjab, Pakistan
}

\begin{abstract}
:
Present study aims to find semantic, pragmatics and cultural equivalence in the source text and the translated text of the selected poetry of Amjad Islam Amjad. The poem that has been selected is "kabhi kabhi habs bhari ratoon main" with English translated version of Michael Burch along under the title 'Every once in a while'. The research design adopted for this study was exploratory and case-based design comprised upon the poetry of Amjad Islam Amjad. One poem in Source language (Urdu) and its translated version (English) was taken through critical case sampling method. The study attempted to explore the frequency and extent of linguistic items equally used in both texts and what is the amount of poignancy and essence in them. The study concludes that significant traces of semantic, pragmatic and cultural transplantation has been found in the source text and translated text of the sample drawn for the analysis.

Subject Words: World Literature in Translation; Linguistic Analysis; Translational Studies. Key words: Semantic, Pragmatic, Cultural Equivalence; Source Text (ST), Translated Text (TT).
\end{abstract}

\section{Introduction}

Aim of the present research is to have Semantic, Pragmatic and Cultural Equivalence in the Source Text and Target Text of the Selected Poetry of Amjad Islam Amjad. Before dealing with the issue, it is necessary to have a better understanding of linguistic terms like that of semantics, pragmatics along with the cultural equivalence. So far as the semantics is concerned it is the branch of linguistics that is concerned with the meanings there are two main areas of semantics one of them is the logical sequence that deals with the matters such as sense and reference as well as the pre-supposition and implementation. There is another branch of semantics that deals with the lexical semantics that is concerned with the analysis of words meanings and their relations with one another. So, it may be said that the branch of linguistics that deals with the issue of meanings of the words and their meanings as well as their relations with one another is called the semantics. In this regard the meanings of words, phrases as well as the text are also included in it. On the other hand, so far as the pragmatics is concerned; it is the branch of linguistics that deals with the language and its use in context is called the pragmatics (Leech 1983). There are matters such as the deixis, taking of turns as well as conversations, organization of text as well as implicative and presuppositions are studied under the study of pragmatics. It is also asserted that there is close relationship of the culture with the language. Even the language of literature has a great deal of effect that shows the culture of the people speaking it. The issue in hand is to have a better analysis of these terms in the light of the selected poetry of Amjad Islam Amjad.

\subsection{Amjad Islam Amjad as Poet}

So far as the writer of the poem selected for the study is concerned, Amjad Islam Amjad was born in Punjab, Pakistan (Dawn, 2019). He basically belongs to Sialkot and got his basic education from that city. He was very active students and was also a cricket player of his college. He completed his degree in Urdu from Punjab University. He started his job in M.A.O College Lahore. At the same time, he also worked as a director of the Pakistan Television Corporation from 1975 to 79. In 1989, Amjad was appointed as Director General of Urdu Science Board. He has also worked as a project director of the Children Library Complex. Amjad is the writer of

${ }^{*}$ Corresponding author

Email address: samaritan_as@hotmail.com (Muhammad Arfan Lodhi)

DOI: https://doi.org/10.31559/BAES2020.5.2.1 
many drama series for Pakistan Television Corporation including Waris. He has written many columns, translation, criticism and essays while his main focus remained writing Nazms, a type of Urdu poetry. Among his most notable dramas are Waris, Dehleez, Samandar, Raat, Waqt and Apnay Loug.

\subsection{Rational of the Study}

The source text has parcel of awesomeness. At the point when it is converted into the English, awesomeness and delicateness decline. With the assistance of this examination, we will talk about non-abrasiveness and grandiosity continued subsequent to making an interpretation of the first content into the deciphered content. There is a contrast between source text and interpreted content culture. At the point when source text is converted into the made an interpretation of text because of culture pressure can't discover such awesomeness as in source text found. According to Skjerdingstad \& Tangeras (2019), readability of poetry in cross-cultural settings as shared readiness enhances the beauty and depth of literature.

\subsection{Research questions}

This research revolves around three research questions:

1. What is Semantic and how it has been used in the selected text of Amjad Islam Amjad?

2. What is Pragmatic and how does it apply to the both translated text and the source text of Amjad Islam Amjad?

3. How does translated text and source text represent culture in Selected Poetry of Amjad Islam Amjad?

\subsection{Significance of the Study}

This research is significant in many ways. At first, it explores the semantic, pragmatic and cultural equivalence in the actual and translated poetry of Amjad Islam Amjad. The discussion and results will help readers to understand the above-mentioned equivalence in source text and target text as has been translated in English language. In a multilingual country like Pakistan, the transliteration and translational texts prove to be intercultural bridge of mutual respect and acceptability among different languages as well as among individuals. The study is also significant in the literature discipline to facilitate the understanding and analytical abilities of the students, teachers and researchers.

\section{Source Text:}

The source text that is aimed to be discussed in the study is the text of Amjad Islam Amjad. It is the text of "khabhi kabhi Habs Bhari ratoon main"

\section{Translated and Target Text:}

The same text has been translated in the English language and it has been translated as "trapped in the suffocated nights". It has been made a struggle to depict that how is the level of poignancy in the text of both languages.

\section{Review of the Related Literature}

\subsection{Poetry of Amjad Islam Amjad}

Ahmad (2009) is of the view that Amjad is a writer having no need of introduction. He is the person widely read in the world mainly in the Muslim world having Urdu as a medium of instruction. He is not only a poet but also a person who worked as a radio playwright. He started his carrier as a teacher at college Lahore. In the later part of his life, he was an appointed at very high seats in educations and cultural organizations. Amjad is regarded to be the person widely read and listened and having a creative mind especially at the place where Urdu is spoken and understood. But at the same time the fame of this personality can never be neglected as a poet as well. His poetry is considered to be one of fine lyrics that are quoted by the young urbanizing section of society. It is easy to comprehend as well as easy to identify especially for the lovelorn youth of society.

Amjad is the person who believes in being the best and he does not believe that those people may prosper in life who has a better past behind them. Even, he believes that people may get fame in their life even if they do not have any fame in their life. Amjad (1982) quoted one of the best examples that while studying he found a list of noble laureates among them there were so many who did not complete even their high school education. As far as the profession of the poet is concerned it has been depicted in an interview by him where he argues that anything may never make him neglect from his profession of a poet. He asserts that at the time when he was doing his television he was dedicated to poetry. He is of the view that due to the blind imitation of the west Muslims have lost their values that are very important for them to act upon. This is what he said at art council Karachi in an interview. Appreciating the work of Amjad Islam Amjad, the Karachi Arts Council organized a function to pay tribute to him. Speaking on the occasion, Amjad Islam Amjad asserted that the tragedy is that our children cannot even write their names in Urdu. The children are being taught that development can only be done in the English Language. "Unfortunately, our film industry has never been given industry status" He added. On the occasion, Amjad Islam Amjad recited his famous ghazals and poems for the audience (ibid). 


\subsection{Equivalence among Source $\&$ Translated Texts}

The theory of similarity and equivalence involves diverse languages for the judgment of the text. In the past fifty years throughout this field, many theories are proposed and expand that are based on equivalence, the main issue in translation could be equity despite its explanation, significance and applicability as well as translation theory caused acute disagreement. Above mentioned theories are commonly divided into three major groups. In the first group, those scholars are kept who obliged the linguistic approach for the translation those who ignore and shows that translation is not just a matter of linguistics. At the same time translator deals with two diverse cultures when a message is moved from SL to TL. It seems that the second group of scholars takes a close eye on this matter and explores the complexities of this feature. Scholars view that translation is a technique of correspondence for the transfer of messages from SC to TC and also a practical approach to translation. The third and last group of translation scholars have a neutral view, for example, Barker (2008) said that the one who proposed the equity is used for convenience because rather than it has any theoretical position many of the translators used it. The process of equality-based during the translation which repeats the same situation as it was before by using different wordings.

They also suggest that the protection can be done on the stylistic effect of SL text in TL text if process applies during translation course. They said that when proverbs idioms, nominal or adjectival phrases clichés and the animal sounds have agreement with translator here equity is the best technique that can be used. They say that the translators find the solution regarding the need for equity that arises from the circumstances in the context of SL text. By all means, they assert that it is not sufficient if in the SL text a semantic equivalence for expression is quoted very well in a glossary or a dictionary and even it does not meet the standard of a thriving translation (Awan n.d.).

They focus on the changes and emphasis on extra-textual factors. They highlighted the broader issue of context, history convention not just argue the faithful in translation rather than explain what is mean by equivalence the purpose of the study has been total changed, for example, the text should be inserted in the network of culture and source signs (Bassnett 2007). Cultural significances are related to the cultural activities moreover 'translator ship' being able to play the social role becoming a translator in the cultural environment, the acquisition of a set of norms for determining the suitability of that kind of behavior and for maneuvering between all factors which may contrast it. (Bassnett 2007). In his book, he writes about travel writing and translation and gives us many examples that travelers and translators are related to another in a dialogue with languages. He introduced term nomadism to take a close eye on similarities between traveler and translator (Bassnett 2007).

In the translation procedure pragmatic equivalence alludes to implicatures and procedures of avoidance. Implicature does not love indirect means. On the other hand, to get the ST message across the work of the translator is changed because it wants to work out a way of meaning in translation. It should be appreciated in another culture for TC readers and it is only the responsibility of the reader to restore the writer's objectives (ibid. p.36). House (1997) discussed that ST and TT should work with another in function and give more importance to pragmatic and semantic equivalence by deciding the situational dimension of the ST, the house says it is possible to type the purpose of the text. If ST and TT are based on the situation of features, after the ST analysis, then they are not working parallel, and the translation is not high level. She admires to utilize an equivalent situationaldimensional aspect to achieve that role rather than the translated text should not only match its source text in the role (Bassnett 2007).

The concept of semantic equivalence that Gottlob Frege proposed in Über Sinn und Bedeutung [On Sense and Reference] (1892) was based on differences in communicative content or effect, which were not to be considered as differences in meaning but as differences in tone (Färbung). According to (ibid) such differences "do not touch the thought" since they are concealing that "color" the informative substance of an articulation without changing whether it is valid or bogus. Language offers numerous instances of articulations that vary in tone however not in meaning: "died-deceased," "cat-kitten," "horse-steed," for example. Every one of these distinctions, which these days are regularly imagined as down to business contrasts, were eliminated based on what swas viewed as the importance of a sentence. Frege assumed of tone as being connected to verse or lovely language, asserting that tone is excessively abstract and accordingly can't have a place with a thorough, careful science "directed toward truth and only the truth" Definitely, Frege's philosophical contemplations on importance had an effect on the meaning of interpretation:

\subsection{Davidson's Theory of Translation}

Davidson actually utilized Frege's idea of semantic comparability and proposed a conventional meaning of interpretation, guaranteeing that $S$ is an interpretation of $S 1$ if $S$ and $S 1$ have a similar truth condition. By applying Alfred Tarski's hypothesis of truth to regular dialects, Davidson (1994) characterized interpretation through semantic equality: $\mathrm{S}$ is valid if and just if $\mathrm{S} 1$ is genuine moreover. For example: "La neige est blancheis valid if and just if snow is white. This is a case of a T-sentence, in Tarskian model (ibid). "The equivalence thesis," which is the premise of the Tarskian model, helped Davidson clarify meaning and the equivalence of importance regarding truth conditions on the planet. In Translation Studies, the idea of equality proposed by John Catford depended on a basically referential hypothesis of importance: he characterized printed identicalness as "ultimately based on similarities of situation substance" (Catford, 1965, p. 91). As Peter Fawcett explained, "the reference to substance 
may seem a little odd, but it stems from the linguistic theory Catford is working with. Writing, sound and the things out there in the world are "substance" Language is an abstract and formal representation of that substance". Be that as it may, in theory of language, the reference to "the things out there on the planet" had been addressed in 1960 by Willard van Orman Quine's notable proposals on ontological relativity and indeterminacy of interpretation.

"The theory Davidson advocates provides a method and a concept of what meaning is, which allows us to make sense of the linguistic and other behavior of other people, and to see how their use of certain sentences relates to their use of certain other sentences" (Malmkjaer, 2005, p. 56). This new hypothesis dismissed the possibility of "invariance of meaning," as in semantic proportionality, and proposed a "second" thought of comparability, which was nearer to Sellars' useful equality and portrayed as the investigation of flashing and everchanging purposes of assembly between a translator and a speaker. Davidson (1984) guaranteed that mediators start attempting to comprehend speakers by utilizing an earlier hypothesis, which communicates how past experience has set them up to decipher a speaker in a given setting. Earlier speculations are endless as per setting, speakers, and translators' desires or their degree of information on a speaker's convictions or expectations, for instance. Translators modify their earlier speculations as per new data originating from an informative experience so as to assemble a passing hypothesis (or a few), which communicates how mediators really get speakers. The "negotiation of meanings" that Davidson (1994) proposed is in this manner endowed to the affectability, instinct and innovativeness of the translator.

\subsection{Brief description of Burch's translational strategies}

Michael R. Burch interpreted Amjad Islam Amjad poem "Every once in a while" in his translation he adopted many strategies such as in the title and a very first line he uses idiomatic and communicative strategy for instance "Every once in a while" is an idiom (Burch n.d.). The reason of the strategy of the use was to make this poem more logical. Idioms are linguistic terms or lexical pieces demonstrating concepts, object or phenomena of physical life specific to a given culture which the writer uses in his interpretation. We can say a string of words whose meaning is different by individual words. The word "Immersed" in his translation is dominating the compensation strategy because it does not exist in the source language. Maybe he wants to show deepness in his feelings, which means making up for the loss of something in sources text by adding something else in the target text. There is clear evidence of transliteration in the third line of the poem such as "Earth voices "in ST earth is not used means when TL equivalent is not available. It is especially concerned with proper names.

Faithful translation technique is used for the word" Have fallen" in the sense of sleep which means to reproduce the precise contextual meaning of the original within the constraints of the TL grammatical structures. It transfers culture words and preserves the degree of grammatical and lexical "abnormality "in a translation. Michael R Burch in his interpretation use word of "Bruised-purple" recognized translation aspect is quite clear by using a well-known accepted target language translation for a specific source language institutional term. "Half sleep "is included in word-to-word translation.

In the sentence" I awaken from a wonderful dream" Modulation translation strategy is used which means variation in the strength, tone or pitch of one's voice; for example, using the name of the category for a specific member of the category using a part for a whole active for passive changing polarity etc. In the second last sentence, omission strategy is used because sometimes no equivalent is available in TT especially culturallybound expressions. For this purpose, one word, a phrase or an expression might be dropped from the ST.

\section{Research Methodology}

The inquiry method used in this research adopted exploratory framework. The aim of this study is to analyze the procedures adopted by Michael R Burch while translating Urdu poem of Amjad Islam Amjad into English version. Exploratory researches are used to investigate the phenomenon under study with logical evidence and substantial argumentative approach. The population framework consisted upon the Urdu poetry of Amjad Islam Amjad and its English translated versions by Burch (n.d.). The sample was drawn from the Urdu written poetry book of Amjad (1982) 'Fishaar'. The English translated version of the similar poem was taken from Burch (n.d.) poem 'Once in a while'. Mixed purposeful sampling technique was applied to determine the sample of the study. In addition, qualitative method of data analysis was used to assess semantic, pragmatic and cultural equivalence in Urdu, which has been translated by Michael R Burch into English language. 


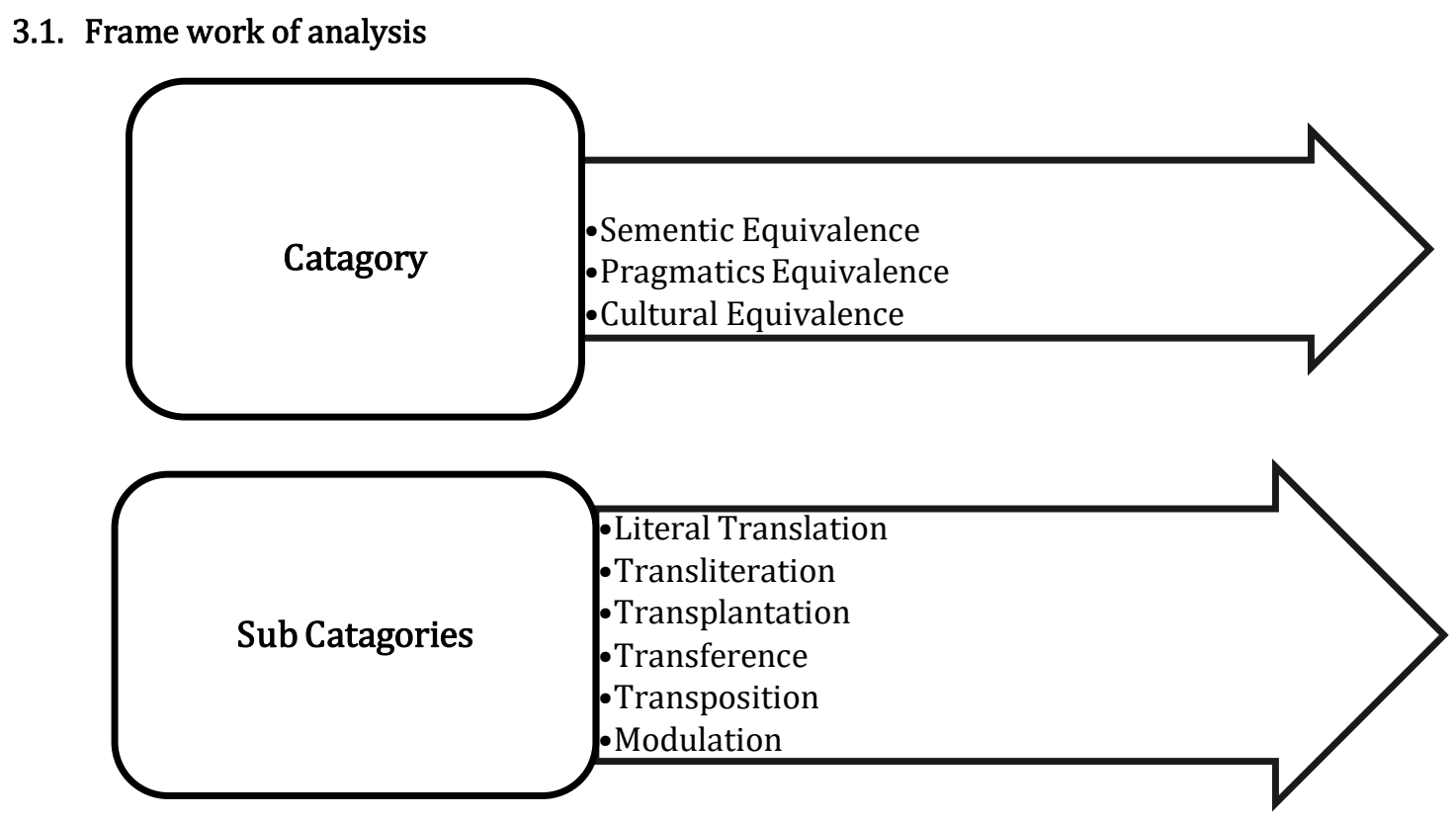

The selected text of the study has been analyzed in the light of the linguistic terms mentioned above. The meanings of semantics, pragmatics as well as cultural presentation have been analyzed in the text of Amjad Islam Amjad. At first these linguistic terms have been applied to the Urdu source text then they have been applied to the English version of the same text and it has been analyzed that how both of the texts are equal in the use of the linguistic items. At the same time, it has also been noticed whether in both of the texts there is equivalency of use and they present the same essence in both these texts or not.

\subsection{Data Collection Sources}

Data has been taken from the poetical compilations of Amjad (1982) and Burch (n.d.). The sample was determined by utilizing mixed purposeful sampling technique i.e. Amjad Islam Amjad's poem "kabhi kabhi" translated by Michael R Burch into English "Once in a while" to analyze the equivalence of both source text and translated text.

\begin{tabular}{|c|c|}
\hline $\begin{array}{l}\text { Every Once in a While } \\
\text { by } \\
\text { Translation/interpretation by Michael R. Burch }\end{array}$ & $\begin{array}{r}\text { By } \\
\text { By كبهى...-. Amjad Islam Amjad }\end{array}$ \\
\hline $\begin{array}{l}\text { Every once in a while, } \\
\text { immersed in these muggy nights } \\
\text { when all earth's voices seem to have fallen } \\
\text { into the bruised-purple silence of half-sleep, } \\
\text { I awaken from a wonderful dream } \\
\text { to see through the veil that drifts between us } \\
\text { that you too are companionless and wide awake. }\end{array}$ & 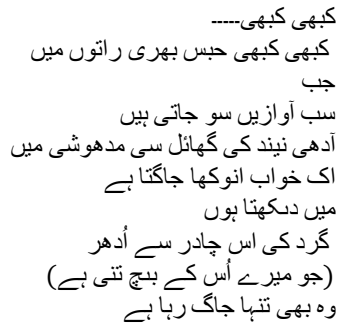 \\
\hline
\end{tabular}

\section{Analysis and Discussions}

\subsection{Semantic analysis of the poem}

- Equivalency in terms of Sense between source and translated text

The poem written in to TT without translating at all the poem written by Amjad Islam Amjad in Urdu has nine lines while the translated poem "once in a while" by Burch (n.d.) has 7 lines. The word written by Amjad Islam Amjad has 49 words but in translated poem there are 50 words. The poet has translated the poem semantically in a fantastic manner but pragmatically he cannot translate it because the culture of source text and translated text both are different. The romantic background and setting in Urdu poem is very fantastic. The selection of words is very good. When the reader reads the English poem, he cannot find the romanticism and loftiness. Though literal translation is available but the Urdu culture is not available in the translated text. It is a fact that the source text is more explanatory and poignant in its essence as compared to the translated text. The essence of the words has more sense in the target language than that of the translated language. The meanings can never be equally conveyed better in the translated text. It seems that there is always a great deal of gap of meanings, sense, text, and context. It is a fact that equivalency of sense is almost impossible in between the source and original text. The essence that an Urdu reader may think and have in the original text of "Habs Bhari ratoon 
main" can never be felt and analyzed in the translated text of "muggy nights" in the same way the Urdu text "Adhi need ki ghayal si madhoshi" it has no semantic equivalency with the translated language. The translated words "half asleep entranced" never leave the same impression of the language as the source text has in itself. The source text has more poignancy in it rather than the translated text. The essence of the words and their meanings that can be better felt in the source text is impossible to achieve in the translated one.

So far as the sense of the poem in translated text is concerned an ordinary overview of the lines that has been translated shows that it is pensive in its sense. The poet is living in a gloom and distressed. The mood of the poet has been strengthened by the depiction of night that is filled with dark that shows that there is harmony in nature and the heart of the poet. Moreover, night looks to the poet that it is nothing but an oppressive one. At the same time, it is nothing but a burden on the poet to lead and pass the night. The poignant atmosphere of the poem shows that poet is not only depressed but also a disappointed and that is the reason that the translation of the poem shows that almost half of the world looks to him that it has fallen asleep and there is complete silence in the atmosphere. The sense of the poem is filled with silence where the poet awakes from a dreamy atmosphere. There is a turn of atmosphere in the poem where the poem suddenly changes his mood and becomes very happy as the dream, he awakes from is very wonderful. The line that has been translated is less in poignancy than the source text. The essence that can be better conveyed by the source text e.g. (habsbhari ratoon main) is less conveyed by the use of words like that of suffocated nights.

- Equivalency in terms of reference between source and translated text

Same is the view that in terms of semantic relationship between the source text and the target text the reference can never be equal to the source text. The harmony of the text and the mood of the poet is better conveyed in the source text rather than the translated one. There has been used a reference of "gard ki chadar" that has been translated as "through the veil" is far away in its meanings. The image of "gard" is more vivid as compared to the "opacity of dust" to the reader. So, it may be stated that the essence of sense as well as the reference is more vivid and clear in the source text is never ever equal to the translated text.

Overall, there has been used so many references in the poem. The references are related to the atmosphere that has a harmony with the mood of the poet. As soon as he thinks that he is gloomy there is night shade in atmosphere and the moment he wakes up he is joyous the reference of atmosphere is also changed all of a sudden. There is complete serenity in the atmosphere as the heart and mind of the poet is at ease whenever he thinks of his beloved. All the world of reality seems to him that it is nothing but a beautiful dream that may happen in the utopia. Although it is a dream but the fact remains that it leaves a great deal of impression on the mind of the reader as well as the writer. The poet is so absorbed by the dreamy atmosphere of the poem that he never wants to come out of this atmosphere and wants to live in this dreamy environment.

\section{- Logical sequence between the translated and source text}

It is an ideal state of thinking that there should be no difference in logical sequence between the source text and the translated text but it is not so. The intended reader of the source text is someone else and the translated text is another body so while translating any piece of literature the logical sequence losses its impact and structure. The poem in hand is of Amjad Islam Amjad from very first word "kabhi kabhi" to the last word "wo bhi tanha Jag rahahal" the logical sequence is at its best. There is an idea being developed and the poet is traveling in the valley of sleep and in the end, he is very happy so there is shift of mood that is better depicted in source text of Urdu as compared to the translation into English. The sequence that has been shown in the original text has its own essence as compared to the translated one. If one peeps into the logical sequence of the poem in translation it has its own appeal.

One of the basic things shown in the poem and related to the semantic analysis of the poem is the logical sequence of the poem. It can be analyzed, even by an ordinary reader of the poem that there is present a logical sequence observed in the poem. As a matter of fact, there is development of thought and suspense in the poem and its translated lines. It can be analyzed that starting from the pensive environment there is an escape from it and it has been made a struggle to find a smooth exit from that situation. The night is suffocated and it is hard for the poet to survive in this environment as he is feeling lonely. Even the idea of being alone makes him more pensive. The logical sequence of the events shows that the dream that he sees at night makes him happy and development of idea has been running smoothly in the poem especially in the translated version of the poem. As soon as he dreams that the beloved is in the same condition as the poet is in there is end of pensive mood and that moment is changed into complete serenity.

- Presupposition and implementation depicted in source and translated text

So far as the presupposition in the poem, mainly in the source text is concerned it is very much in the poem in hand. The minor view of the poem in the source text shows that there is always, from beginning to the end the pensive mood and environment of the poem. The words "habs bhari ratoon main" shows that since the atmosphere is of darkness so it is likely to remain and sustain for a great deal of time. The poet is to live in this mood for a great deal of time but the very next moment the poet seems to be happy as soon as he dreams that his beloved one is also in seclusion.

Semantic analysis also includes the presupposition of the events of the poem. It has been noticed that there is really an environment depicted in the poem that is related to the presuppositions and that environment has been implemented in the poetry of Amjad Islam Amjad. How the presupposed environment has been depicted in it is 
clear from the tone of the poem mainly as depicted in the lines translated. At times there is shift of mood that is not expected all of sudden. The sleeping mood and dreamy environment when the poet from a gloom passes to happiness due to an idea that he is not only alone and living the life in seclusion but also his beloved one is also in the same condition and he is thinking of the same idea as poet shares. As he is a companionless person same is the condition of the beloved one of the poets. He shares the same experiences as the poet thinks and shares.

\section{- Analysis of words meanings and their relation with one another}

The source as well as the translated text of the poem shows that at both levels the poem does not leave its lexical relationship. The relation of the text in both source and the translated one is at its best but the target reader has been changed and there is a shift of mood in both. Apart from the logical sequence, in the source text it does not seem that the poet has struggled to choose the words and sentences rather it looks that the words and their meanings are clear to him and he does not have to work a lot for their selection. The words are at his beck and call.

In translated text of the poem there it has been analyzed that the words have been chosen with a great deal of thinking and contemplation. All the words are apt at their place. Not a single word seems to be superfluous rather it is at its proper place. If one word is displaced the whole edifice of the translated version of the poem is changed and disturbed. Semantic relation of the words with one another is like an organic whole. The words and sentences have been organized in a good and beautiful manner. All the sentences are interrelated to one another and they convey their meanings with a great deal of reference and context. The mood of the poet and atmosphere of the poem is a dreamy one and all the words suit that mood and atmosphere. The words are chosen which are accordingly with the mood of the poet. So, in the translated text there has been struggled that the same essence should be depicted as the source text depicts.

\subsection{Pragmatics analysis of the poem}

There are different levels of the poem where it can be analyzed on pragmatic level. All these levels are there to use texts, the source and the translated, in its social context. It is also a pragmatic study of the text if there are some turns in it and the study of those turns is a pragmatic study of language. At the same time the organization of the text also falls under the category of pragmatic. The study aims to investigate whether there is pragmatic equivalency between the source text and translated text of the poem in hand.

- The language and its use in context

All the languages of the world have their own social context and their own vocabulary used in different contexts. Some of the languages are their where one word is used in different contexts and some are so strict that the use of word is also strict with them and there are not more than one meaning and social contexts for them. The poem in hand is of Amjad Islam Amjad who is Urdu poet. The original text of the poem is vast in its context. The word of "Habs" has so many meanings in it. This word may refer to the suffocation of the poet where the poet may feel difficulty to even inhale. At the same time this word contextually may also refer to the inner mood of the poet where he may feel as unhappy and pensive and due to this reason, he may face a problem of inhaling and it seems to him that he will not be able to breathe. The outer atmosphere, even the air has become uneasy for him. This word, when translated with suffocated in English has limited context and meaning and that is to feel difficulty in breathing. In the same way the Urdu sentence "jab sab awazain so jati hen" has its own essence as well as its context in Urdu that is different when translated into "when all earth voices seem to have fallen" so it is hard to believe that the source text and the translated text has same equivalence in pragmatics and context of the language that is vivid from the text of the poem in hand.

\section{- Taking of turns in conversations}

Pragmatics is also a study of taking turns in usual conversation and mood. At times the mood of the speaker takes turns. This turn of mood may transfer from pensive to happy and vice versa or loud tone to the low tone of speaking. So far as the mood of the poet depicted in the poem is concerned it is same as depicted in the pragmatics. One of the basic things that may lead to the reader to have an analysis of the poem is that the poet switches from pensive and gloomy mood to the happy one. He was very "immersed" at the beginning of the poem and there was "Habs" felt by him. But this mood is changed at the end of the poem and he feels happy when he gets up from a dream and finds his companion as alone and secluded as he in himself. But so far as the taking of this turn in translated language and original and source language is concerned it is different from one another. They are not equal in sense rather they are different. The source text is more vivid in its expression of the turn as compared to the translated language or text is concerned. All of a sudden, the mood of the poet is changed and it is converted towards happiness as he sees his beloved or the loved one as alone and companionless as he is. Although it is against the ethics of the lover that he should be happy to find beloved entity alone rather he should have been burning in his passionate love alone but it does not happen.

\section{- Organization of text and implication}

Organization of the text is studied under the pragmatics. The source text is so much well organized that it can be analyzed by an ordinary reader that it has a proper begging, middle and end. In the beginning there is an atmosphere that is going to the serenity and in the beginning all the sounds are asleep and there is complete peace in the atmosphere and there is almost darkness where one may prepare himself to go to the valley of sleep. The sentence like "adhi need ki ghayal si madhoshi" is a time when the poet is feeling sleepy and he wants to travel in 
that valley. Suddenly there is a dream and waking with happy mood looking and thinking about the beloved who is also alone and in seclusion.

- Relation of language and culture

There is a close relationship of the culture with the language. Even the language of literature has a great deal of effect that shows the culture of the people speaking it. As far as the source text of the poem is concerned there have been used so many words which show the culture of a particular nation or race. The word of "chadar" is never used in any other language of the world. It is the local word of those living in the villages especially and then as a whole it is a typical Urdu word. That "chadar" is used in its original sense and it is used in a sense that "ye tani hui haiy". At the same time if one peeps into the use of this word in the English context it will be giving different meanings. The words like that of beyond the opacity of dust that "drift between us" is never ever equal to the use of this sentence in Urdu source text.

\section{Conclusion}

After the analysis of the text presented in the both languages it has been analyzed that the amount of poignancy as well sense that is conveyed in the source text is more vivid and clear as compared to the translated text. The essence that reader finds in the Urdu text of Amjad Islam Amjad is no more found in the translated version of the text. If, there is any amount of essence it is never equal to the source text. So, it may be said that the source text of any language has more understanding and words in their original sense have more power over the translated text.

After the semantic, pragmatic and cultural analysis of the text it may be concluded that there is significant difference present at all linguistic levels. The tone of the translated text is always different than that of the source text. It is also concluded that the essence of any language that is regarded to be the source language or the source text is altogether different from the translated text. The reason to this is that the target reader of the any language is different. The sense, reference, context, meanings, poignancy, atmosphere, the expression of feelings and emotions in any language are different from one another and they differ from language to language. Same is the case with the source text and the translated text of poem in hand written by Amjad Islam Amjad.

\section{References}

1. Ahmad, Aijazuddin (2009). Geography of the South Asian Subcontinent: A Critical Approach. Concept Publishing Company. p. 119. ISBN 978-81-8069-568-1.

2. Ahmad, Irfan (2017). Religion as Critique: Islamic Critical Thinking from Mecca to the Marketplace. UNC Press Books. ISBN 978-1-4696-3510-1.

3. Amjad, I. A. (1982). Fishaar. Cited in Rekhta. https://www.rekhta.org/poets/amjad-islam-amjad/ebooks.

4. Awan, M. S. (n.d.). "Authors "Introduction Literary Globalization and the Politics and Poetics of Translations."

5. Bassnett, Susan. (2007). "Culture and Translation." A Companion to Translation Studies 13-23.

6. Burch, M. (n.d.). Every Once in a While. https://allpoetry.com/poem/15443250-Urdu-Poetry-Translations-by-Michael-R.-Burch retrieved on 26th April 2021.

7. Catford, J. C. (1965). A Linguistic Theory of Translation. Oxford University Press.

8. Davidson, D. (1984). Inquiries into Truth and Interpretation. Oxford: Oxford University Press.

9. Davidson, D. (1994). The Social Aspect of Language. In B. McGuinness \& G. Oliveri (eds.), The Philosophy of Michael Dummett 1-16. Dordrecht: Kluwer Academic Publishers.

10. Dawn (2019). "Why did the Quaid make Urdu Pakistan's state language? |ePaper| Dawn.com". epaper.dawn.com. Retrieved 3 December 2019.

11. Frege, G. (1892). 'Über Sinn und Bedeutung', in Zeitschrift für Philosophie und philosophische Kritik, 100: 25-50; translated as 'On Sense and Reference' by M. Black in Geach and Black (eds. and trans.), 1980, 56-78.

12. Hakala, Walter (2012). Languages as a Key to Understanding Afghanistan's Cultures. Afghanistan: Multidisciplinary Perspectives.

13. Leech, G. N. (1983). Principles of Pragmatics. Routledge

14. Malmkjaer, K. (2005). Translation and Linguistics. Perspectives Studies in Translatology13(1):5-20. DOI: $10.1080 / 09076760508668960$.

15. Raj, Ali (2017). The case for Urdu as Pakistan's official language. Herald Magazine. Archived from the original on 28 October 2019. Retrieved on 10 October 2020.

16. Skjerdingstad \& Tangerås (2019). Shared reading as an affordance-nest for developing kinesics engagement with poetry: A case study. Cogent Arts \& Humanities, 6(1): 1688631, https://doi.org/10.1080/23311983.2019.1688631. 